\title{
Memória e identidade docente de uma professora surda do Ensino Superior
}

\author{
Zilda Maria de Oliveira Lana* \\ Fernanda Grazielle Aparecida Soares de Castro** \\ Stela Maria Fernandes Marque****
}

\section{Resumo}

Este artigo tem por objetivo apresentar e analisar relatos da trajetória docente de uma professora surda do Ensino Superior, buscando tecer consideraçóes sobre sua memória e sua identidade docente. Para isso, são discutidas questóes como as conquistas da comunidade surda, as mudanças no cenário educacional para os surdos e, ainda, aspectos teóricos sobre a formação da memória e da identidade docente. Caracteriza-se como um estudo de natureza qualitativa, no qual os relatos foram coletados por meio de entrevista semiestruturada. Essa entrevista foi gravada em vídeo e posteriormente analisada. Os dados obtidos da professora surda permitem observar que sua memória e sua identidade profissional constituem-se de aspectos diversos de ordem pessoal, profissional e de luta pelos direitos dos surdos. A entrevistada declara que, apesar de mudanças terem acontecido, com melhorias para o acesso ao ensino superior e à formação docente para surdos, ainda são necessárias reflexôes e ações de reconhecimento e inserção dos surdos no Ensino Superior.

Palavras-chave: Memória; Identidade docente; Pessoas com surdez.

\footnotetext{
* Mestranda em Educação pela Pontifícia Universidade Católica de Minas Gerais, Minas Gerais, Belo Horizonte, Minas Gerais, Brasil.

** Mestranda em Educação pela Pontifícia Universidade Católica de Minas Gerais, Minas Gerais, Belo Horizonte, Minas Gerais, Brasil.

*** Professora doutora da Pontifícia Universidade Católica de Minas Gerais, Minas Gerais, Belo Horizonte, Minas Gerais, Brasil.
} 


\section{Memory and professional identity of a deaf leacturer}

\section{Abstract}

This article aims to present and analyze reports of teaching trajectory of a Higher Education deaf lecturer and seeks to discuss her memory and professional identity. To do so, we discuss such issues as the achievements of the deaf community, changes in the education for the deaf, as well as, theoretical aspects on memory formation and teacher identity. This is a qualitative study and data was collected through semi -structured interviews. This interview was recorded on video and later analyzed. The data collected during the deaf lecturer's interview allow us to understand that her memory and her professional identity are comprised by various aspects of personal and professional order and by the fight for the rights of the deaf.. The interviewed lecturer stated that, despite the changes that occurred, which led to improved university access and teacher education for the deaf, we still need to ponder and to have measures of recognition and integration of the deaf in Higher Education.

Keywords: Memory; Teacher identity; Deaf people.

\section{Introdução}

Durante vários anos, a surdez foi tema de estudos quase que exclusivos da medicina. Sendo considerada como deficiência, aos surdos associava-se uma imagem de inferioridade. No entanto, após a militância desse grupo e as conquistas legislativas, mudanças têm acontecido e novos campos de pesquisa têm surgido, com interesses diversos, tais como a investigação da construção da memória e da identidade de pessoas com surdez.

Uma das conquistas dos surdos foi o acesso à educaçáo e a possibilidade de formação docente. Nesse caminho de formação, os surdos docentes confluem, para a formação de sua(s) identidade(s), fatores múltiplos, de ordem social, profissional e individual. Torna-se, portanto, interessante analisar as apreensóes e as construçóes identitárias de docentes surdos.

Logo, o presente trabalho trata da memória e da identidade profissional de uma professora surda do Ensino Superior, apresentando um pouco de sua trajetória e sua percepção sobre a profissão docente e a inserção e permanência dos surdos na área.

\section{Objetivo}

Este trabalho tem por objetivo apresentar algumas reflexôes sobre a memória e a identidade profissional de uma professora surda do Ensino Superior, expondo um pouco sobre sua trajetória profissional e de sua "militância" em prol da formação acadêmica para pessoas com surdez e do reconhecimento como profissionais docentes. 


\section{O reconhecimento da surdez no brasil - algumas mudanças importantes}

Segundo Silva (2012), até pouco tempo, a surdez era considerada uma deficiência que deveria ser tratada e analisada apenas sob a perspectiva da medicina. No entanto, quebrando esse paradigma, atualmente se vislumbra uma mudança de olhar para a questão dos surdos na sociedade. Assim, outros estudos, para além da medicina, que tratam, por exemplo, da construção da identidade surda, juntamente a mudanças legislativas, têm conferido às pessoas com surdez mais dignidade e possibilidade de formação e de reconhecimento.

O movimento dos surdos tem algumas referências de luta pelo reconhecimento cultural, pela busca de conquista de autonomia e inserção social e profissional na sociedade. Dentre elas, cita-se, dentre outros, a Federaçáo Nacional de Educação e Integração dos Surdos (FENEIS), o Instituto Nacional de Educação de Surdos (INES), o Instituto Phala, que têm lutado para que os direitos e as conquistas da comunidade surda sejam firmados na sociedade.

No âmbito da educação, mudanças também têm surgido.

A primeira escola para surdos, chamada de Instituto dos Surdos Mudos, criada em 1856 por Ernest Huet (PINTO, 2006), caracterizava-se por um ensino dependente de caridade e com orientaçóes diferenciadas para aqueles que tinham resíduos de surdez e para os completamente surdos (PINTO, 2006), sem preocupação em reconhecimento da linguagem própria desse grupo de pessoas. Soares (1999) ${ }^{1}$ citado por Pinto (2006) expóe de forma interessante que a educação dos surdos era tida como caridade porque atendia a um grupo peculiar de pessoas, que nem podia frequentar escolas "normais" recebendo instruçôes devidas, já que esse era o destino de pessoas "sem deficiência", e nem se enquadravam como baderneiros e vagabundos, a quem náo deveria ter acesso à escola. Dessa forma, os surdos estariam entre esses "dois grupos" e, assim, seriam dignos de caridade, pois, apesar de não frequentarem as escolas, não eram baderneiros/vagabundos, devendo lhes ser concedido auxílio e caridade.

Na década de 1880, o Congresso de Milão, trouxe mudanças na concepção de ensino para os surdos. O trabalho de Baalbaki e Caldas (2011) mostra reflexão sobre esse evento. $\mathrm{Na}$ oportunidade, assumiu-se que a surdez não se relacionava a problemas fisiológicos, vertente imperante até então, passando-se então a pensar que os surdos não teriam problemas para falar. Dessa premissa, valorizaram a fala oral e escrita, pregando que essas seriam desenvolvidas com a prática. Observa-se aí que há certa anulação da identidade surda, tentando apagá-la e impondo a oralidade como língua principal.

Dois séculos passaram-se e o cenário mudou consideravelmente. Apesar de ainda carecer de muitas transformações, vivencia-se atualmente uma maior inserção dos surdos no ambiente educacional, com reconhecimento de uma identidade própria, tanto como discentes, quanto como docentes. 
Em 1996, no Rio Grande do Sul, o Núcleo de Pesquisa em Políticas Educacionais para Surdos (NUPPES), ligado ao Programa de Pós-graduação da Universidade Federal do Rio Grande do Sul, formou os primeiros surdos mestres e doutores do país, além de formular currículos para a Secretaria de Educação do Estado e atuar na formação de professores (SILVA, 2012). Em 2006, a Universidade Federal de Santa Catarina implantou o primeiro curso de Letras Libras a distância, possibilitando a formação de profissionais em diferentes regiôes do país e formando 1079 pessoas (PÊGO; LOPES, 2014). Mais recentemente, em 2013, a Universidade Federal do Rio de Janeiro anunciou a abertura de cursos de graduação presenciais voltados para a formação em Língua Brasileira de Sinais (Libras) (SOUZA; TOURINHO, 2013).

Adicionadas a essas estruturaçôes nas instituiçôes de ensino, mudanças legislativas também indicam um marco de conquistas para a comunidade surda. A Lei ${ }^{\circ}$ $10.436 / 2002$ e o Decreto no 5.626/2005, que a regulamenta, configuram importantes conquistas no que diz respeito aos aspectos profissional e de formação educacional para os surdos.

A referida Lei no 10.436/2002 firmou a língua de sinais como língua materna, a primeira língua para os surdos, e o português como segunda, estabelecendo oficialmente o ensino bilíngue para surdos. Além disso, a Libras passa a ser oficialmente meio legal de comunicação e expressão, com previsão de inclusão nos sistemas de ensino municipais, estaduais e federais.

De forma complementar, o Decreto no 5.626/2005 trata sobre a necessária formação docente para a atuação como professor de Libras nas escolas, conferindo prioridade de formação aos surdos para ministrar disciplinas em cursos de nível superior. Prevê também a inclusão da Libras em cursos de formação de professores, pedagogia e licenciaturas e obriga as instituiçóes federais de ensino a garantirem acesso à educação para os surdos. Por fim, mas sem esgotar a discussão, fica caracterizada a diferenciação entre a formação de professores e a formação de intérpretes, garantindo ao professor surdo reconhecimento como profissional docente.

Considerando essas mudanças, faz-se interessante saber sobre a formação da identidade e da subjetividade dos profissionais docentes surdos, uma vez que o caminho percorrido por cada um deles carrega sentimentos compartilhados pela comunidade de pessoas com surdez, que lutam por ideais comuns, e também sentimentos, experiências e formaçóes próprias, que dizem sobre suas particularidades.

\section{Breves apontamentos sobre a memória e a identidade docente}

As construçóes de memória e identidade de uma pessoa formulam-se por meio de um processo relacional em que diversos fatores atuam. São resultantes de relaçôes sociais, individuais e profissionais, (LINHARES, 2006).

Entende-se por identidade um processo contínuo e dinâmico, que implica a produçáo de sentidos e a (re)interpretação dos próprios valores e experiências. A identidade relaciona-se com o ser reconhecido por si e pelos outros como um determina- 
do modo de pessoa, em um dado contexto e na relação com o outro. É um processo que envolve a identidade natural (origem do indivíduo), a identidade institucional (posição ocupada em um ambiente organizacional), a identidade discursiva (características pessoais que marcam a relaçấo com os outros) e a identidade de filiaçâo (acesso a um conjunto de práticas distintas que são de interesse comum) (GOMES, et al., 2013).

No processo de construção da identidade, a memória é fator importante, e até determinante, representando marcas e símbolos capazes de guiar as interpretaçóes de fenômenos e orientar os caminhos e as decisóes a serem seguidas pelas pessoas, encaminhando para a ocorrência de mudanças e de transformaçôes. Transformaçóes essas que

[...] se dão ao longo de tempo de vida de cada indivíduo, constituindo uma singularidade que se identifica e se diferencia em relação a si mesmo em diferentes momentos, assim como se aproxima e se distancia de outros indivíduos em momentos diferentes ou iguais. A memória se modifica e se rearticula conforme a posição que ocupo e as relações que estabeleço nos diferentes grupos de que participo. A memória também está submetida a questões inconscientes, como o afeto, a crítica, enfim, está inserida num fluxo de sentimentos. As memórias individuais alimentam-se da memória coletiva e histórica e incluem elementos mais amplos do que a memória construída pelo indivíduo e seu grupo. (LINHARES, 2006, p. 33).

Articulando-se com a memória, o tornar-se professor envolve a transformação da identidade docente em um processo dinâmico (GOMES, et al., 2013) Dessa forma, a identidade do profissional docente é construída por uma multiplicidade de fatores. Dentre esses, pode-se destacar aqueles de formação e representação coletivas, ou seja, que são construídos por um processo histórico de atribuição social de valores que confere, por exemplo, maior ou menor "status social". E também as representações individuais, que são construídas pelas apropriaçóes específicas que cada profissional faz de seu contexto social e de trabalho.

Ainda em relação à constituição da identidade docente, na ótica de Gatti (1996 apud BRZEZINSKI, 2002, p. 9), a identidade do professor é fruto de interaçôes sociais complexas nas sociedades contemporâneas e expressão sociopsicológica que interage nas aprendizagens, nas formas cognitivas, nas açóes dos seres humanos. Ela define um modo de ser no mundo, num dado momento, numa dada cultura, numa história.

Placco (2006), ao discutir a aprendizagem do adulto professor, define a formação identitária como:

um processo de construção e desconstrução, formação e deformaçâo, um movimento que o docente assume formas identitárias, via processo de identificação e não-identificação com as atribuiçóes que lhe são dadas por si mesmo e pelos outros com quem se relaciona. Nesse movimento, há constantes atos e sentimentos 
de pertença e nâo-pertença, estreitamente relacionados à subjetividade, à memória, a processos metacognitivos, aos saberes e experiências de pessoas singulares e do grupo. (PLACCO et al., 2006, p. 21).

Como bem aponta Contreras $(2002)^{2}$ citado por Lages (2011), o exercício prático do magistério traz especificidades que impedem a comparação irrestrita a outras profissóes.

O professor coloca em ação os conhecimentos que individualmente é capaz de construir, assim como aqueles também compartilhados com outros professores, o que implica a necessidade de se construir uma profissionalidade fundamentada na reflexão individual e coletiva. (LAGES, 2011 p. 2).

No contexto da docência, é fundamental que os professores compreendam que são sujeitos em permanente desenvolvimento, pois assim, construirão sua identidade profissional, influenciada por aspectos de natureza social e individual, podendo experimentar suas possibilidades e seus limites, ou seja, se envolverem com as situaçôes de ensino capazes de favorecer a reflexão acerca das atividades pedagógicas no contexto de sua prática cotidiana e social (BOLZAN; ISAIA; MACIEL, 2013).

Assim como a identidade do docente é construída a partir de representaçóes sociais, coletivas e individuais, a identidade do surdo também o é. E nesse sentido, pode-se dizer que há aqui duas representaçóes bem díspares sobre a identidade de pessoas com surdez. Aquela que surge do coletivo, em sua maioria dos ouvintes, que caracteriza o surdo como deficiente, como diverso. E a representação dos surdos que se reconhecem como diferentes e não como deficientes e nem diversos.

Reis (2013) traz interessante contribuição ao apresentar estudos de Skliar $(2010)^{3}$, dizendo que pensar os surdos como diversos carrega um sentido de que no diverso hospeda-se a normalidade, donde se concluiria que a surdez seria uma condição anormal. Essa premissa distancia-se da própria visão da comunidade surda, já que um dos elementos que os caracteriza é a diferença (SKLIAR, 2010 apud REIS, 2013), visto que no diferente não há inferiorização, mas, ao contrário, a afirmação de algo que difere de outro sem por isso ser superior ou inferior.

"As culturas diferem entre si, mas não deixam de ser cultura. Assim como existe a cultura indígena, a cultura oriental, a cultura africana, existe também a cultura surda, com suas identidades possíveis" (REIS, 2013, p. 66). Ao considerar o surdo como diverso ou deficiente, assume-se que há um outro normal e, por trás dessa premissa, a falácia de que se deve aproximar os surdos da normalidade, do padrão ouvinte, sendo necessário, para isso, que sejam concedidos cuidados especiais, que seja concedida caridade, benevolência. Já o surdo como diferente luta por direitos de se manter diferente, sem necessária aproximação e/ou comparação com outra cultura, apenas se reconhecendo e sendo reconhecido como diferente.

Por fim, considerando os fatores até então discutidos, a identidade do professor surdo constitui-se em meio às questóes levantadas, confluindo aquelas que per- 
passam a identidade docente, bem como as que constituem a identidade das pessoas com surdez. Importante, porém, não perder de vista as características individuais/ pessoais que também perfazem a identidade do profissional docente surdo.

Sintetizando, no trabalho de Silva (2012), é exposto que para falar sobre as identidades surdas, e aqui amplia-se para falar da identidade surda docente, há vários marcadores que podem ser articulados, tais como a língua de sinais, a luta dos surdos pelo reconhecimento de seus direitos, a luta pelo cumprimento de seu direito de acesso à educação e à formação acadêmica e docente.

\section{Metodologia}

O presente trabalho é de natureza qualitativa e foi desenvolvido por meio de entrevista semiestruturada realizada com uma professora surda que atua no ensino superior.

Bodgan e Biklen (1994) elencam características que definem os estudos qualitativos. Dentre elas, citam-se aquelas que evidenciam a natureza do presente trabalho. A sabe: o recolhimento de dados feito por palavras e imagens, e não números, incluindo vídeos, entrevista e sua respectiva transcrição; toda a riqueza e a forma com que os dados foram registrados, foram consideradas para a análise, sem a realização de compilados e nem transformaçóes numéricas; a narrativa da entrevistada não foi transformada em símbolos numéricos, mantendo-se os pormenores de suas falas; e ainda, os investigadores foram os instrumentos principais para a coleta dos dados, oriundos da fonte direta de informaçáo, qual seja a entrevistada.

Para a entrevista, foi elaborado um roteiro com questôes abertas. A escolha dessa modalidade de coleta de dados ocorreu em virtude de permitir ambiente de maior interaçáo e fluidez entre o entrevistado e o entrevistador, sem imposição rígida ao primeiro, e permitir que o participante exponha de forma mais livre sua apreensão e suas consideraçôes sobre o tema e as questôes propostas (LUDKE; ANDRÉ, 1986).

A entrevista foi gravada em vídeo e uma tradução com legenda foi adicionada à gravação. Os dados coletados foram analisados e serão expostos no tópico seguinte.

\section{Apresentação e análise dos dados}

Neste tópico, serão apresentadas as questôes norteadoras da entrevista, bem como as reflexôes realizadas a partir das colocações da professora surda.

As perguntas foram:

Questâo norteadora no 1 - Relate um pouco sobre sua trajetória acadêmica e profissional na educação.

A professora entrevistada tem grande experiência na produção de materiais didáticos e ensino de Libras. É pesquisadora, com textos e artigos publicados. Atualmente trabalha no ensino superior, mas já atuou no ensino básico como pedagoga e professora. 
Logo no início da entrevista, a professora inicia sua fala firmando-se como surda, apresentando a Libras como sua língua e enfatizando a importância do seu reconhecimento como língua oficial e primeira dos surdos, seguida da língua portuguesa, em um sistema bilíngue de comunicação. Nesse sentido, conforme disse Silva (2009), um traço importante que define o grupo cultural dos surdos é exatamente a Libras, pois o compartilhar dessa língua é de fundamental importância para permitir a interação entre os surdos e a sua firmação como diferentes, e não deficientes.

Esse aspecto remete à importância da língua para a constituição da identidade surda. Pensar a língua e a identidade requer a concepção de que o desenvolvimento do reconhecimento do Eu é um processo semiótico, que pressupóe necessariamente relaçóes interpessoais. A identidade só pode então ser pensada considerando-se a dinâmica de sentidos e significados produzidos na interação com o outro. Para isso, o papel da linguagem é constitutivo, porque um sujeito constrói-se em seus modos de linguagem e nos modos de linguagem do outro. No caso do surdo, em particular, o sistema bilíngue de comunicação, referenciado pela entrevistada, pressupóe uma perspectiva socializada, que abandona as práticas clínicas e terapêuticas, as quais firmam os surdos como deficientes (GESUELI, 2006).

A comunicação bilíngue alinha-se com a concepção socioantropológica, segundo a qual a surdez é compreendida como experiência visual (SKLIAR, 1999), fragilizando ideias preconcebidas sobre a normalidade. Essa experiência visual não se restringe a uma capacidade de produção e compreensão especificamente linguísticas ou a uma modalidade de processamento cognitivo, mas se traduz em todos os tipos de significações, representações e/ou produçôes do surdo, no campo intelectual, linguístico, ético, estético, artístico, cognitivo, cultural, entre outros (GESUELI, 2006).

Nesse sentido, a discussão sobre identidade surda não se desvincula da cultura surda, que se relaciona ao processo de recriação de um espaço cultural visual. Os surdos legitimam sua língua e sua comunidade e, como decorrência dessa convivência minoritária, há o nascimento da cultura surda (arte, humor, teatro, poesia etc.) (GESUELI, 2006). A identidade surda é concebida dentro de uma cultura visual e isso precisa ser compreendido não como uma construção isolada, mas como construção multicultural (PERLIN, 1998).

A professora entrevistada atua no ensino de Libras desde o ano de 1981, quando cursava biblioteconomia e era a única surda na faculdade em que estudava. Nessa época, declara que tinha conhecimento de que apenas mais duas pessoas haviam frequentado o ensino superior, sendo um formado em engenharia e outro em direito. Interessante apontar aqui os dados divulgados pelo Inep/MEC em 2011e discutidos por Daroque e Padilha (2012), que ilustram a necessidade de aprimoramento nas mudanças de acesso e permanência no ensino superior por pessoas surdas. Apesar das mudanças que vêm ocorrendo, a comunidade surda no país com acesso ao ensino superior representa apenas cerca de $7 \%$ da totalidade.

Seguindo, durante um tempo, a entrevistada declarou ter atuado acompanhando os serviços de um professor conhecido que trabalhava em uma clínica de 
fonoaudiologia, onde tinha muito material didático em inglês sobre Libras, utilizado pelo próprio professor. Dos estudos desse material didático em inglês, a professora entrevistada, juntamente a seu amigo que trabalhava na clínica, começou a desenvolver apostilas para o ensino de Libras. O professor que tinha um grupo de estudos com surdos na clínica solicitou à entrevistada que o auxiliasse trabalhando como professora de Libras na clínica. Isso aconteceu até o ano de 1986.

Além disso, trabalhou também na FENEIS utilizando os próprios materiais sobre Libras produzidos e os disponibilizando para venda, cujo retorno financeiro serviria para contribuir com a própria Federação. Mesmo não havendo ainda a língua de sinais oficialmente instituída, continuou, com sua equipe de trabalho, produzindo as apostilas com base nas informaçôes de textos e livros importados, contribuindo assim com a formação de aproximadamente cinco mil alunos nos cursos de Libras da FENEIS.

Em 1994, já formada em pedagogia, participando das reunióes da FENEIS, presenciou a proposta de que os surdos devessem trabalhar como instrutores no ensino. Diante da proposta, posicionou-se de maneira contrária, já que acreditava que os surdos deveriam ter formação pedagógica e trabalhar como professores, e não instrutores. Apesar de sua discordância, cedeu à proposta e os surdos começaram a trabalhar como instrutores. Mas sua concordância com a decisão de inserção dos surdos no ensino como instrutores não acalentou sua movimentação para que pudessem trabalhar como professores. Nota-se que, nessa época, no ano de 1994, não havia legislação que amparasse o trabalho dos surdos com formação pedagógica como professores. Comparativamente, nos dias atuais, pode-se considerar que a comunidade dos surdos conquistou o direito de atuar e serem reconhecidos como professores.

Faria (2011) faz interessante reflexão e problematiza a questão que envolve o reconhecimento do professor surdo como tal, com formação pedagógica, uma vez que o Decreto no 5.626/2005 permite ao intérprete atuar como professor nas instituiçôes de ensino, ainda que provisoriamente. Isso, segundo a autora, vai contra a Lei de Diretrizes e Bases da Educação, Lei no 9394/1996, que prevê a necessidade de formação específica, como nas licenciaturas, para atuação nas salas de aula como professor. No entanto, não se pode esquecer que, apesar da conquista e do reconhecimento como professores, é preciso ampliar mais o acesso e a permanência dos surdos no ensino superior, e talvez a permissão, em curto prazo, de intérpretes seja coerente com a situação de matrículas de alunos surdos no ensino superior, que ainda é baixa, conforme demonstrado anteriormente.

A professora entrevistada ressalta que, apesar das conquistas na legislação, como a Lei $n^{\circ} 10.436 / 2002$ e o Decreto no 5.626/2005, o conhecimento sobre ela ainda é precário, principalmente em escolas e instituiçôes de ensino superior, ambientes nos quais é fundamental que se conheça e se lute pelos direitos dos surdos.

Outras conquistas importantes citadas pela entrevistada foram: 1- o fato de o governo seguir com a igualdade de salários, pois é inadmissível que professores surdos tenham remuneraçôes ou salários mais baixos apenas pelo fato de serem surdos, 
o que ainda acontece em outros países. 2- e a realização, em 2014, do primeiro congresso brasileiro de professores surdos universitários, que contemplou a discussão de diversos temas como currículo, carga horária e obrigatoriedade ou não da disciplina de Libras.

Seguindo na trajetória profissional, em 1996, a entrevistada deixou a FENEIS e participou da criação da LSB vídeos, em que eram produzidos materiais como DVDs, livros e apostilas para surdo, além da oferta de cursos de Libras.

Boa parte do grande trabalho desenvolvido pela professora entrevistada relaciona-se à produção de materiais didáticos que possam ser utilizados pelos surdos e que também sejam capazes de auxiliar na ampliação e difusão do conhecimento da língua de sinais pela comunidade ouvinte.

Observa-se que a entrevistada faz uma recomposição de sua trajetória de atuação como docente e militante, resgatando as bases legais, sociais e pedagógicas do surdo na educação, considerando, para isso, sua memória. Deparando-se com as suas lembranças, a entrevistada traz de suas memórias marcadores que vão delineando e sustentando a sua trajetória profissional, construindo teias de significados sobre a sua história e refletindo sobre a sua identidade como docente (SILVA; SIRGADO; TAVIRA, 2012). Aqui, portanto, pode-se observar as implicaçôes da memória na constituiçáo da identidade docente surda, a partir de um processo dialético que as torna indissociáveis (THOMSON, 1997).

Questão norteadora no 2 - Além dos problemas conhecidos na profissão docente, como falta de recursos, baixos salários, precariedade das instituições, que atinge a toda a categoria profissional, você enfrentou dificuldades de inserção no mercado de trabalho, tais como preconceito, em virtude de sua surdez? Em caso afirmativo, quais foram as principais?

Você já atuou profissionalmente no ensino básico? Em caso afirmativo, poderia brevemente discorrer sobre essa experiência? Encontrou resistências em virtude da surdez nesse período?

Solicitada que falasse sobre a questão do preconceito ainda associado à visão que considera os surdos como deficientes e menos capazes, a entrevistada afirma que nem na universidade nem no ensino básico sofreu qualquer tipo de preconceito ou resistência em virtude de sua surdez. Interessante que declarou como dificuldades apenas aquelas associadas à classe dos professores e que atinge a todos independentemente de serem surdos ou ouvintes.

Apontou como dificuldades, enquanto atuou no ensino básico, a necessidade de acumular extensa carga horária, em virtude de baixos salários, falta de reconhecimento, e excesso de trabalho com remunerações que não condiziam com o trabalho realizado. Ou seja, observa-se que são dificuldades que não se associam exclusivamente aos professores surdos, mas que atingem a grande maioria dos docentes.

A professora acredita que as maiores dificuldades, no que se refere à comunidade surda na educação, estão no ensino superior, em que há mestres e doutores que 
desconhecem sobre o sujeito surdo. Além disso, as próprias instituiçôes também não conhecem as legislaçôes e, ao elaborarem editais, precisam se conscientizar e procurar informações com pessoas surdas sobre especificações necessárias que não discriminem a comunidade surda e lhe garanta o direito de participar com isonomia das seleçóes.

Outra dificuldade apontada pela entrevistada diretamente relacionada à surdez na profissão docente refere-se à participação dos surdos nas provas de concurso. Acredita que as pessoas com surdez sejam prejudicadas, pois ao invés de fazerem prova em língua portuguesa e Libras, deveriam fazer apenas em Libras, já que o Português seria sua segunda língua.

Esse aspecto remete à relevância da aceitação da língua materna do surdo e, consequentemente, de sua cultura e identidade nos concursos realizados. Aceitar uma língua implica sempre a aceitação de uma cultura e, nesse caso, o que se pode perceber é a negação das especificidades dos surdos; a negação de sua língua, sua cultura e sua identidade. Há, portanto, um investimento no apagamento da diferença, mas onde há apagamento há também resistência. E, nesse sentido, em consonância com a entrevistada, hoje muito surdos resistem aos seus apagamentos; eles têm se fortalecido, alcançado algumas conquistas, buscando o reconhecimento de sua cultura e tentando fazer-se presente como minoria linguística, ainda que fragmentado pelo grupo que se submete à hegemonia cultural (GESUELI, 2006).

Questão norteadora no 3- Em sua opinião, as instituições de ensino básico e superior estáo preparadas para receber os professores surdos? Em caso negativo, o que você acredita faltar para que ocorra essa inserção, tanto do ponto de vista quantitativo, quanto qualitativo?

A respeito da inserção do professor nas instituiçôes, a professora acredita que já houve uma melhora significativa na formação de professores surdos. No entanto, é necessário que seja ampliada e melhorada. E nesse sentido, considera ser muito importante a ampliação dos cursos e das vagas em nível superior de Letras-Libras, por exemplo, possibilitando aos surdos que trabalham como tradutores/intérpretes passem a se constituir professores.

Diante do exposto, nota-se que a ampla experiência profissional e de luta pela possibilidade e pelo reconhecimento dos surdos como professores marcam a identidade docente da professora entrevistada. Tanto aspectos pessoais, como suas aspiraçóes, quanto aspectos sociais e culturais contribuíram para a constituição de sua memória e sua identidade docentes.

Nesse sentido, o relato da entrevistada denota a constituição multifacetada da identidade docente e a sua íntima articulação com os marcadores de memória resgatados. Esses marcadores tecem seus distintos modos de atuação como docente surda, desde o início de sua trajetória na área, registrando limitaçôes e potencialidades. Assim, a identidade da docente surda mostrou-se e se mostra em vias de uma construção permanente que tanto estabelece fronteiras identificatórias entre ela e o outro quanto busca, ao longo de sua trajetória, o reconhecimento dos demais membros sociais a que pertence (SANTANA; BERGAMO, 2005). 


\section{Considerações finais}

A realização desta pesquisa contribuiu para a compreensão de fatores que influenciaram a formação da identidade docente da professora entrevistada. Foi possível perceber a influência de fatores sociais, como as mudanças impressas pelas legislaçôes, e as dificuldades enfrentadas pelos docentes, como baixos salários e jornadas exaustivas. Além disso, o trajeto profissional traçado pela professora também foi determinante para a construção de sua identidade. Interessante também notar sua firmação como surda, explicitando ser a Libras sua forma de comunicação oficial, sua primeira língua.

Por fim, mesmo considerando que melhoras já ocorreram, a necessidade de mais mudanças e de reconhecimento dos surdos como diferentes e igualmente capazes de se inserirem no mercado profissional ainda é recorrente, em especial na área docente, sendo necessária melhor estruturação das universidades para expandirem seus cursos de formação docente, como o Letras-Libras.

\section{Referências bibliográficas}

BAALBAKI, A.; CALDAS, B. Impactos do Congresso de Milão sobre a língua dos sinais. Cadernos do Congresso Nacional de Linguística e Filologia, Rio de Janeiro, v. 15, n. 5, p. 1885-1895, 2011.

BODGAN, R. C.; BIKLEN, S. K. Investigaçáo qualitativa em educaçáo. Portugal: Porto Editora, 1994.

BOLZAN, D. P. V.; ISAIA, S. M. A.; MACIEL, A. M. R. Formação de professores: a construçáo da docência e da atividade pedagógica na Educaçăo Superior. Revista Diálogo Educacional, Curitiba, n. 13, n. 28, p. 49-69, jan./abr. 2013.

BRASIL. Lei no 9394, de 20 de dezembro de 1996. Estabelece as diretrizes e bases da educação nacional. Diário Oficial da União, Brasília, 20 de dezembro de 1996.

Lei no 10.436, de 24 de Abril de 2002. Dispõe sobre a Língua Brasileira de Sinais - Libras e dá outras providências. Diário Oficial da União, Brasília, 25 abr. 2002.

Decreto no 5.626, de 22 de Dezembro de 2005. Regulamenta a Lei no 10.436, de 24 de abril de 2002, que dispóe sobre a Língua Brasileira de Sinais - Libras, e o art. 18 da Lei no 10.098, de 19 de dezembro de 2000. Diário Oficial da União, Brasília, 23 dez. 2005.

BRZEZINSKI, I. Profissão professor: identidade e profissionalização docente. Brasília: Plano, 2002.

DAROQUE, S. C.; PADILHA, A. M. L. Alunos surdos no ensino superior: uma discussão necessária. Comunicaçóes, ano 19, n. 2, jul./dez, p. 23-32, 2012.

FARIA, J. G. Formação, profissionalização e valorização do professor surdo: reflexôes a partir do Decreto 5.626/2005. Revista Brasileira de Educaçáo Especial, Marília, v. 17, n.1, jan./abr., p. 87-100, 2011.

GESUELI, Z. M. Lingua(gem) e identidade: a surdez em questão. Educaçáo e Sociedade, Campinas, v. 27, n. 94, p. 277-92, jan./abr. 2006

GOMES, C. P. P.; et al. A identidade profissional do professor: um estudo de revisão sistemática. Revista Brasileira de Educação Física e Esporte, São Paulo, v. 27, n. 2, p. 247-67, 2013.

LAGES, I. L. P. A profissão docente e a construção da identidade na educaçăo infantil: problemas desse e de outros tempos. In: VI CONGRESSO DE PESQUISA E ENSINO DE HISTÓRIA DA EDUCAÇÃO EM MINAS GERAIS, 2011, Viçosa/MG. Anais... Viçosa. Disponível em: <http://www.cch.ufv.br/copehe/trabalhos/ind/Ilma.pdf>. Acesso em 05 dez. 2014.

LINHARES, E. V. Marcas da memória traduzidas na identidade docente: relatos de vida de professoras alfabetizadoras. 2006. 164p. Dissertação (Mestrado) - Centro de Educação de Ciências Humanas e da Comunicação, Universidade do Vale do Itajaí, Itajaí, SC.

LUDKE, M.; ANDRÉ, M. E. D. A. Pesquisa em educação: abordagens qualitativas. São Paulo: EPU, 1986. 
PERLIN, G. Identidades surdas. In: SKLIAR, C. (Org.). A surdez: um olhar sobre as diferenças. Porto Alegre: Mediação, 1998.

PINTO, F. B. O silencioso despertar do mundo surdo brasileiro. Fênix - Revista de História e Estudos Culturais, ano III, v. 3, n. 2, abr./mai./jun., 2006. Disponível em: <http://www.revistafenix.pro.br/PDF7/03\%20 ARTIGO\%20FERNANDAPINTO.pdf >. Acesso em 04 dez. 2014.

PLACCO, V. M. N. S.; SOUZA, V. L. T. (Orgs.). Aprendizagem do adulto professor. São Paulo: Loyola, 2006.

PÊGO, C. F.; LOPES, B. Reflexôes acerca do curso de letras libras e suas contribuiçôes para a construção de novas perspectivas na educaçăo a distância. In.: XI Congresso Brasileiro de Ensino Superior à Distância, 2014, Florianópolis/SC. Anais ESUD/2014... Disponível em: <http://esud2014.nute.ufsc.br/anais-esud2014/files/ pdf/128085.pdf>. Acesso em 30 jan. 2015.

REIS, D. S. Formaçáo docente e educaçáo de surdos: um encontro com a diferença, cultura e identidade surda. 2013. 174p. Dissertaçáo (Mestrado). Universidade Federal de Rondônia. Porto Velho, RO.

SANTANA, A. P.; BERGAMO, A. Cultura e identidade surdas: encruzilhada de lutas sociais e teóricas. Educação e Sociedade, Campinas, v. 26, n. 91, p. 565-82, Maio/Ago. 2005.

SILVA, B. G. da. Memória e narrativas surdas: o que sinalizam as professoras sobre sua formação? 2012. 128p. Dissertação (Mestrado). Universidade Federal de Pelotas. Pelotas, RS.

SILVA, D. N. H.; SIRGADO, A. P.; TAVIRA, L. V. Memória, narrativa e identidade profissional: analisando memoriais docentes. Caderno Cedes, Campinas, v. 32, n. 88, p. 263-83, Set./Dez. 2012.

SKLIAR, C. Atualidade da educaçáo bilíngue para surdos. Porto Alegre: Mediação, 1999.

SOUZA, J.; TOURINHO, N. UFRJ cria primeira graduaçáo presencial em Libras do Rio de Janeiro. Disponível em <http://www.ufrj.br/mostranoticia.php?noticia=14512_UFRJ-cria-primeira-graduacao-presencial-em-Libras-do-Rio-de-Janeiro.html\#>. Acesso em 04 dez. 2014.

THOMSON, A. Recompondo a memória: questốes sobre a relaçẫo entre a História Oral e as memórias. Projeto História, São Pau

\section{Notas}

${ }^{1}$ SOARES, M. A. L. A Educaçáo do Surdo no Brasil. Bragança Paulista, São Paulo: EDUSF, Editora Autores Associados, 1999.

${ }^{2}$ CONTRERAS, J. A autonomia de professores. São Paulo: Cortez, 2002.

${ }^{3}$ SKLIAR, C. (Org.). A surdez: um olhar sobre as diferenças. 4 ed. Porto Alegre: Mediação, 2010.

\section{Correspondência}

Zilda Maria de Oliveira Lana - Escola Municipal Ana Amélia Queiroz. Rua Petúnia, s/n., Gutierrez, CEP: 35450-000, Belo Horizonte, Minas Gerais - Brasil.

E-mail: zildalana@yahoo.com.br - fernandagas1@gmail.com - sm.pucminas@gmail.com

Recebido em 27 de abril de 2015

Aprovado em 10 de julho de 2015 